\title{
POR UMA EDUCAÇÃO MINIMAMENTE INCLUSIVA: O USO DO NOME SOCIAL PARA TRAVESTIS E TRANSEXUAIS NAS ESCOLAS DO ESTADO DE SÃO PAULO
}

\author{
Tassio Acosta ${ }^{1}$ \\ Eduardo Meinberg de Albuquerque Maranhão Filho ${ }^{2}$
}

\section{RESUMO}

Apresenta-se neste artigo algumas considerações a respeito do uso do nome social em ambiente escolar, com especial enfoque no estado de São Paulo. Para tal, realiza-se uma análise de marcos legais referentes ao uso do nome social por travestis e transexuais neste estado, bem como de registros quantitativos de discentes que se identificam a partir destas duas categorias identitárias de gênero. $O$ estudo mostra-se relevante por ser o primeiro a mapear quantitativamente a existência de transexuais e travestis nos bancos escolares entre o período de 2016 a 2019, em todos os níveis de ensino do estado de São Paulo. Conclui-se que há a necessidade de capacitar os funcionários das escolas para melhor reconhecer as especificidades da comunidade transexual e travesti, assim como para possibilitar maiores condições da manutenção de seus direitos civis, evitando a evasão e possibilitando a escolarização desta parcela da sociedade.

\footnotetext{
${ }^{1}$ Mestre em Educação pela Universidade de São Carlos - UFSCar. Doutorando em Educação (Unicamp). Docente da Universidade Santa Cecília. ORCID: http://orcid.org/0000-00021608-4363. Lattes: http://lattes.cnpq.br/9459372033217997 E-mail: tassiogde@gmail.com

${ }^{2}$ Doutorado em História Social pela Universidade de São Paulo - USP. Pós-Doutorado Interdisciplinar em Ciências Humanas (Universidade Federal de Santa Catarina - UFSC), em Ciências das Religiões (Universidade Federal da Paraíba - UFPB) e em História (Universidade Federal de Santa Catarina - UFSC). Docente Visitante no Programa de PósGraduação em Direitos Humanos e no Departamento e Centro de Ciências Jurídicas da Universidade Federal da Paraíba (PPGDH/UFPB; DCJ-CCJ/UFPB). Atua na Presidência da Associação Internacional de Estudos de Afetos e Religiões (AMAR). Coordena a FOGO Editorial, editora especializada em Gênero e Religião, Afeto e Educação. ORCID: https://orcid.org/0000-0002-4808-9345 Lattes: http://lattes.cnpq.br/7589132071776933 E-mail: edumeinberg@gmail.com
} 
Palavras-chave: Nome Social. Travestis e Transexuais. Educação Inclusiva.

\section{FOR A MINIMALLY INCLUSIVE EDUCATION: THE USE OF THE SOCIAL NAME FOR TRANSVESTITES AND TRANSSEXUALS IN THE SCHOOLS OF THE STATE OF SÃO PAULO}

\section{ABSTRACT}

This article presents some considerations regarding the use of the social name in a school environment, with a special focus on the State of São Paulo. To this end, an analysis is made of legal frameworks regarding the use of the social name by transvestites and transsexuals in this State, as well as quantitative records of students who identify themselves from these two gender identity categories. The study is relevant because for being the first one to quantitatively map the existence of transsexuals and transvestites in school environments, between2016 to 2019, at all levels of education in the State of São Paulo. We conclude that there is a need to train school staff to better recognize the specificities of the transsexual and transvestite community, as well as to enable greater conditions for the maintenance of their civil rights, avoiding evasion and enabling the education of this part of Society.

Keywords: Social Name. Transvestites and Transsexuals. Inclusive Education.

\section{PARA UNA EDUCACIÓN MÍNIMAMENTE INCLUSIVA: EL USO DEL NOMBRE SOCIAL PARA TRAVESTIS Y TRANSEXUALES EN ESCUELAS DEL ESTADO DE SÃO PAULO RESUMEN}

\section{RESUMEN}

Este artículo presenta algunas consideraciones sobre el uso del nombre social en un entorno escolar, con un enfoque especial en el Estado de São Paulo. Con este fin, se realiza un análisis de los marcos 
legales con respecto al uso del nombre social de travestis $y$ transexuales en este estado, así como los registros cuantitativos de los estudiantes que se identifican a partir de estas dos categorías de identidad de género. Su importancia se debe a que es el primer estudio que mapea cuantitativamente la existencia de transexuales y travestis en bancos escolares, entre el período de 2016 a 2019, en todos los niveles de educación en el Estado de São Paulo. Concluimos que existe la necesidad de capacitar al personal de la escuela para reconocer mejor los detalles de la comunidad transexual y travesti, así como para permitir mayores condiciones para el mantenimiento de sus derechos civiles, evitando la evasión y permitiendo la educación de esta parte de la sociedad.

Palabras clave: Nombre Social. Travestis y Transexuales. Educación Inclusiva.

\section{INTRODUÇÃO}

Analisaremos neste texto a totalidade dos dados referentes ao uso de nome social para travestis e transexuais em ambientes escolares localizados no estado de São Paulo, no período entre 2016 e 2019. Para tal, utilizaremos como arcabouço alguns marcos legais e registros quantitativos relativos à presença de estudantes que se identificam como transexuais e travestis.

Ao pensarmos sobre este artigo, nos atentamos para a existência dos dados quantitativos de requerimentos para uso de nome social por transexuais e travestis em sua fase escolar. Inicialmente, não fizemos nenhum tipo de recorte, com o intuito de mapear, em todos os anos escolares, onde houve requerimento e em qual período ocorreu maior demanda.

Esta possibilidade só se deu graças à Lei do Acesso à Informação (BRASIL, 2011), sancionada em 18 de novembro de 2011, pela então Presidenta Dilma Rousseff. A Lei N. 15.527 permite que qualquer pessoa tenha acesso a uma vasta quantidade de informações - apenas são impedidos de acesso os dados referentes à questão de segurança do país ou que contenham algum nível de sigilo. Tal legislação mostra-se importante por disponibilizar uma 
vasta quantidade de dados disponíveis para consulta e pesquisa, como é o caso deste trabalho em tela.

Metodologicamente, buscou-se analisar todos os requerimentos realizados no estado de São Paulo de acordo com faixas etárias, assim como a partir de quem se deu a requisição, desde a primeira inserção até a do momento da consulta abarcando o período entre 2016 e 2019. As análises evidenciaram a existência de erros explícitos na coleta e cadastramento dos dados por parte dos órgãos públicos e, após tabelarmos todas as informações e entrarmos em contato com a Secretaria Municipal de Educação [de São Paulo], informando do erro, fomos comunicados da existência real deste erro de sistematização da informação e que novos treinamentos seriam realizados com a equipe das escolas responsável por cadastrar tais informações no sistema.

Reconhece-se a importância deste trabalho por quatro motivos, são eles: i) em virtude de seu ineditismo, uma vez que inexiste um levantamento quantitativo a nível estadual (São Paulo) mapeando a quantidade de cadastramento discente na categoria de transexuais e travestis; ii) a catalogação quantitativa de todos os requerimentos de acordo com os seus níveis de ensino; iii) o amplo período histórico (do primeiro registro, em 2016, até o último, em 2019) e iv) por termos identificado um erro presente na catalogação dos dados da Secretaria Municipal de São Paulo.

Ainda neste sentido, autores como Pelucio e Miskolci (2009), Duque (2011), Andrade (2012), Acosta (2016, 2019) e Gonçalves da Silva e Lionco (2019) pontuam as dificuldades existentes e vivenciadas por travestis e transexuais em virtude de suas identidades de gênero e expressões de gênero não serem respeitadas na escola, uma vez que a instituição busca normatiza-las, muitas vezes silenciando-as e marginalizando-as e, apenas o fato de ali se fazerem presentes nos bancos escolares, pode-se ser interpretado enquanto forma de resistência ao CIStema ${ }^{3}$.

Não obstante, reconhece-se a existência de cada vez mais jovens às margens da heteronormatividade e cisnormatividade, levando-nos a reconhecer que a escola vem vivenciando mudanças

\footnotetext{
${ }^{3}$ Realiza-se aqui uma 'brincadeira' entre as palavras sistema e cisnormatividade.
} 
sistemáticas em suas constituições, favorecendo para que jovens às margens da normatividade social possam ter maiores possibilidades de exercer seus direitos civis e viverem suas vidas com menores riscos.

Para os pesquisadores Marco Torres e Marco Aurélio Prado (2014), a escola se constitui enquanto um elemento não muito acolhedor para transexuais e travestis, necessitando resistir às normas e criar escapes necessários para as suas manutenções nos bancos escolares. Para eles, "é preciso entender o funcionamento dos dispositivos das normas de gênero, como a transfobia, na regulação das dinâmicas inter-relacionais" (p. 217) para pensarmos em outras escolas possíveis, outros dispositivos institucionais menos discriminatórios e mais respeitosos às diferenças.

Por fim, nesta seção introdutória, pontua-se que este texto está dividido da seguinte forma: após esta breve introdução, procuraremos "definir" o que é o uso do nome social, para então contemplarmos alguns dos marcos legais referentes ao seu uso em âmbito nacional. A seguir, referiremos marcos legais relativos à utilização do nome social no estado de São Paulo, trazendo ainda um levantamento quantitativo de alunes ${ }^{4}$ transexuais e travestis em São Paulo.

Tais registros, apresentados ao longo do trabalho, comprovam a existência de pessoas transexuais e travestis (por meio da requisição do nome social em seus registros escolares), dados aqui apresentados na forma de gráficos. Tal seção foi dividida em duas subseções, uma referente ao estado de São Paulo e a outra, ao município de São Paulo. Algumas considerações acerca do assunto dão fechamento ao nosso trabalho.

\footnotetext{
${ }^{4}$ Utiliza-se aqui a letra $e$ (alunes) ao invés de $a$ (alunas) e de $o$ (alunos) para visibilizar não somente as autoidentificações binárias (feminina e masculina) de gênero como as autopercepções de pessoas não-binárias. Pessoas não-binárias são aquelas que não se identificam $100 \%$ nem no sistema sexo-gênero feminino e nem no masculino, como mencionado em nota anterior. Pessoas transexuais e travestis podem se identificar tanto como pessoas binárias como pessoas não-binárias.
} 


\section{MARCOS LEGAIS SOBRE A UTILIZAÇÃO DO NOME SOCIAL NO ÂMBITO FEDERAL}

Podemos compreender nome social como aquele pelo qual pessoas transgêneras (termo entendido aqui como condição sociopolítica de inadequação às expectativas sociais referentes ao sistema sexo-gênero outorgado ao nascer) preferem ser chamadas cotidianamente, expressando suas identidades e subjetividades de gênero (bem como suas autoidentificações específicas, como travesti, homem trans, mulher transexual, não-binárie, ${ }^{5}$ etc). O nome social é utilizado se contrapondo à denominação registrada no nome civil, dado ao se "reconhecer" o sistema sexo-gênero da pessoa, com o qual a pessoa não se identifica.

Seguem, agora, algumas resoluções sobre o uso do nome social em âmbito federal. Em relação à Administração Pública Federal, é sabido que "o uso do nome social tem sido legitimado por diversas entidades governamentais", dentre elas, "a Administração Pública Federal, através do Ministério do Planejamento, Orçamento e Gestão, assegura, pela Portaria $n^{\circ} 233$, de 18/05/10, o uso do nome social por travestis e transexuais, em determinadas situações." (MARANHÃO Fo, 2013, p. 33).

Também em nível federal, no âmbito da saúde, a partir da Portaria GM 1820/2009, artigo 4º o Ministério da Saúde dispõe sobre os direitos e deveres dos usuários da saúde, "garantindo o direito de "identificação pelo nome e sobrenome civil, devendo existir em todo documento do usuário e usuária um campo para se registrar o nome social, independente do registro civil sendo assegurado o uso do nome de preferência, não podendo ser identificado por número, nome ou código da doença ou outras formas desrespeitosas ou preconceituosas"."

Além disto, "o Conselho Federal de Serviço Social, através da Resolução CFESS 615, de 8/09/11, dispõe sobre a inclusão e uso do nome social da/o assistente social travesti nos documentos de identidade profissional.", e a "Resolução 14/2011, do Conselho

\footnotetext{
${ }^{5}$ Não-bináries, ou pessoas não-binárias, são aquelas que não se identificam integralmente nem como mulheres, nem como homens.
} 
Federal de Psicologia, assegura às pessoas transexuais e travestis o direito de inclusão do "prenome que corresponda à forma pela qual se reconheça e é identificada, reconhecida e denominada" em seu meio social" (MARANHÃO Fo., 2013, p. 33).

Em relação à esfera da educação, que nos interessa mais diretamente aqui,

O Ministério da Educação (MEC), através do Parecer Técnico 141/2009, responde favoravelmente à comunicação interna 652/2009 do Gabinete da Secad, que encaminha memorando com solicitação da ABGLT (Associação Brasileira de gays, bissexuais, lésbicas, travestis e transexuais) para manifestação por meio de Resolução à medida adotada por estados e municípios em relação à adoção do nome social em registros escolares. Portaria $\mathrm{n}^{\circ} .1 .612$ do Ministério da Educação, de 18/11/11, assinada pelo então ministro Fernando Haddad e publicada pelo Diário Oficial da União n 222 de 21/11/11, assegura "o direito à escolha de tratamento nominal nos atos e procedimentos promovidos no âmbito do Ministério da Educação", entendendo por nome social "aquele pelo qual essas pessoas se identificam e são identificadas pela sociedade", garantindo $\mathrm{o}$ uso do nome social mediante requerimento da pessoa interessada" (MARANHÃO Fo, 2013, p. 34).

Para fins de contexto, vale nuançar ainda que, já no início da década de 2010 o uso do nome social por discentes era adotado por universidades e institutos educacionais, como Universidade Federal do Amapá (UNIFAP), Universidade Federal do Paraná (UFPR), Universidade Federal de Santa Catarina (UFSC), Instituto Federal de Educação, Ciência e Tecnologia de Santa Catarina (IFSC), e Universidade Nacional de Brasília (UnB).

Como exemplo, podemos citar Marcelo Caetano da Costa Zoby, que em 20 de setembro de 2012, "ganhou o direito" de usar o nome social na UnB, abrindo precedente na instituição, porém "corroborando uma concepção autorizativa do uso do nome social: Os órgãos públicos, com maior ou menor "benevolência", 
reconhecem e "permitem" este tipo de direito" (MARANHÃO Fo, 2013, p. 34).

Entretanto, os marcos legais no âmbito federal para a utilização de nome social nas instituições escolares infelizmente são demasiadamente recentes. A primeira resolução a respeito desta demanda no Conselho Nacional de Educação - Conselho Pleno, foi publicada somente em 2017, (CNE/CP 14/2017), tratando da normatização nacional sobre o uso do nome social na educação básica. Já a segunda, também do CNE/CP 19/2018, define o uso do nome social de pessoas transgêneras, especificamente de travestis e transexuais, ${ }^{6}$ nos registros escolares. Não há quaisquer outros marcos legais no âmbito federal que se refiram à utilização de nome social para transexuais e travestis no período escolar.

O primeiro marco legal, o CNE/CP 14/2017, inicia o documento valorando que a "busca pelo princípio da igualdade jurídica e pelo reconhecimento social da diversidade sexual tem sido a tônica" do movimento $\mathrm{LGBT}^{7}$ há mais de três décadas e, para atender a demanda do nome social de alunes transexuais e travestis, as Instituições de Ensino Superior (IES), os Conselhos Estaduais e Municipais, o Ministério da Educação (MEC), por meio da Secretaria de Educação Continuada, Alfabetização, Diversidade e Inclusão (Secadi) e Conselho Nacional de Educação (CNE) se somaram ao

${ }^{6}$ Considera-se aqui o termo transgeneridade como a condição sociopolítica de inadequação a normas e expectativas sociais relativas ao sistema sexo-gênero outorgado no nascimento ou na gestação. Transgeneridade não trata-se de uma identidade. Este termo serve como "guarda-chuva" para autoidentificações específicas, dentre elas, as autodeclarações identitárias de pessoas transexuais e travestis. Para maiores informações: Lanz (2014) e Maranhão Fo. (2014).

7 A sigla acolhe três orientações sexuais específicas (lésbicas, gays e bissexuais, representadas pelas letras $L G B$ ) e uma condição sociopolítica de inadaptação ao sistema sexo-gênero designado no nascimento ou gestação ( $T$, de pessoas transgêneras). Há controvérsias e discussões acerca do uso da sigla. Há quem prefira o uso de três Ts (TTT), incluindo além das pessoas transgêneras, as identidades específicas travesti e transexual, enquanto outras aderem aos dois Ts, somente de travestis e transexuais (TT). Outras concepções incluem as pessoas que se percebem como queer $(Q)$, as pessoas intersexo (I) e outras pessoas (+) que não são cisgêneras e não são heterossexuais (LGBTQI+). Para informações sobre o histórico de produção desta autêntica "sopa de letrinhas", representativa da elaboração de orientações sexuais e identidades de gênero coletivas nos anos 1990, recomenda-se: Facchini (2005). 
movimento com o intuito de responder aos anseios dessa parcela populacional.

Faz-se um amplo relato histórico no CNE/CP 14/2017, começando pela adoção de nome social pelo Sistema Único de Saúde (SUS), ainda em 2006. Utilizaram também a Portaria $n^{\circ} 233$, de 18 de maio de 2010, do Ministério do Planejamento, Orçamento e Gestão no qual se permite a utilização de nome social no âmbito da Administração Pública Federal direta, autárquica e fundacional. $\mathrm{O}$ mesmo ocorre com o Decreto Federal $n^{\circ}$ 8.727, de 28 de abril de 2016, que dispõe sobre o uso do nome social e o reconhecimento da identidade de gênero de pessoas travestis e transexuais também no âmbito da administração pública federal direta, autárquica e fundacional - em seu artigo $3^{\circ}$, afirma-se que:

os registros dos sistemas de informação, de cadastros, de programas, de serviços, de fichas, de formulários, de prontuários e congêneres [...] deverão conter o campo "nome social" em destaque, acompanhado do nome civil, que será utilizado apenas para fins administrativos internos.

Ainda de acordo com este primeiro marco legal, a Secretaria Estadual da Educação do Pará foi a pioneira na adoção ${ }^{8}$, influenciando a Universidade Federal do Amapá para disponibilizar a utilização do nome social para seu corpo discente - o que não traria grandes entraves jurídicos por se tratar de jovens maiores de idade. Mas, e os menores de idade? O Grupo Dignidade ${ }^{9}$ requereu a extensão dos direitos para menores de idade, sobretudo inferiores a 16 anos, para a utilização do nome social mediante autorização de seus responsáveis.

Posto isto, o CNE/CP $14 / 2017^{10}$ se preocupou com o fato de

as estatísticas de violência e abandono da escola em função de bullying, assédio, constrangimento,

\footnotetext{
${ }^{8}$ Disponível em https://www.abglt.org/para acesso em 31 jan. 2020

${ }^{9}$ Disponível em https://www.grupodignidade.org.br/\# acesso 10 mar. 2021

${ }^{10}$ Disponível http://portal.mec.gov.br/index.php?option=com_docman\&view =download\&alias $=7292$ 1-pcp014-17-pdf\&category_slug=setembro-2017-pdf\&ltemid=30192 Acesso em: 06 fev. 2020.
} 
preconceito, além de outras formas de discriminação, que podem ser minimizadas pela adoção do nome social e pelo respeito à identidade de gênero desses estudantes (p. 7)

Buscou-se pautar a adoção do nome social enquanto uma política pública de Direitos Humanos para, ainda de acordo com o CNE/CP 14/2017, assegurar a

possibilidade do nome social também para os menores de 18 anos, sem prejuízo, portanto, do desenvolvimento de campanhas educativas e outras medidas para combater a violência contra travestis, transexuais e outras orientações sexuais nas escolas brasileiras (BRASIL, 2017, p. 8).

O projeto final resolve:

Art. $3^{\circ}$ Alunos maiores de 18 anos podem solicitar o uso do nome social durante a matrícula ou a qualquer momento sem a necessidade de mediação.

Art. $4^{\circ}$ Alunos menores de 18 anos podem solicitar o uso do nome social durante a matrícula ou a qualquer momento, por meio de seus representantes legais, em conformidade com o disposto no artigo 1.690 do Código Civil e no Estatuto da Criança e do Adolescente. (BRASIL, 2017, p. 10).

Realça-se aqui que, ainda que pretendendo-se inclusivo, o CNE/CP 14/2017 utiliza-se de linguagem androcêntrica, reforçando o masculinismo, como em "alunos", quando poderiam ter utilizado linguagem não-binária de gênero (como em alunes) ou minimamente acolhendo as pessoas que se identificam no feminino (alunas).

Já o segundo marco legal a nível Federal, a Resolução n 1 de 19 de janeiro de $2018^{11}$, define o uso do nome social de travestis e transexuais nos registros escolares, e em sua primeira consideração reconhece que o "pressuposto da legislação, ao possibilitar o nome

${ }^{11}$ Disponível em http://www.direito.mppr.mp.br/arquivos/File/rcp001_18.pdf acesso em 06 fev. 2020 
social aos com maioridade legal, após uma década, não logrou inteiramente os objetivos de impedir a evasão escolar, decorrente dos casos de discriminação, assédio e violência nas escolas em relação a travestis e transexuais" (BRASIL, 2018, p. 1), mesmo reconhecendo a existência das diversas legislações estaduais com o intuito de proteger travestis e transexuais, como também:

que a diversidade sexual e o respeito à identidade de gênero são congruentes com os valores universais da contemporaneidade democrática, e que o Brasil é signatário desses valores em razão do compromisso nacional e da assinatura em diversos acordos internacionais de direitos humanos (BRASIL, 2018, p. 2).

Valoriza-se ainda o reconhecimento da utilização do nome social por estudantes transexuais e travestis podendo impactar positivamente em suas vidas, pois a inteligibilidade entre o corpo e a identidade da pessoa (tanto a partir da autoidentificação e heteroidentificada) são de grande importância para o respeito aos Direitos Humanos. Resolve-se, logo em seu primeiro artigo:

na elaboração e implementação de suas propostas curriculares e projetos pedagógicos, os sistemas de ensino e as escolas de educação básica brasileiras devem assegurar diretrizes e práticas com o objetivo de combater quaisquer formas de discriminação em função de orientação sexual e identidade de gênero de estudantes, professores, gestores, funcionários e respectivos familiares. (BRASIL, 2018, p. 1).

Nesta nota é novamente perceptível a linguagem binária tendendo sempre ao referente masculino (professores, gestores, funcionários, respectivos), ao invés de um linguajar que privilegie não somente um gênero mas sim, com condições de acolhimento de todas as autoidentificações generificadas. Isso se estende a provavelmente todas as resoluções legais que se pretendem inclusivas (mas não se utilizam de linguagem inclusiva).

O passo dado nesta resolução é de grande importância pelo fato de se reconhecer a necessidade e importância de a escola pensar 
sobre as especificidades dessa parcela populacional, sobretudo ao evidenciar a importância da questão ainda no âmbito da 'elaboração e implementação de suas propostas curriculares e projetos pedagógicos'.

Luma de Oliveira, professora da Universidade da Integração Internacional da Lusofonia Afro-Brasileira (UNILAB), costumeiramente reconhecida como a primeira travesti doutora no Brasil $^{12}$ e referência nas lutas dos direitos das transexuais e travestis, afirma:

o nome negado significa o não acesso aos espaços educacionais, portanto se trata de uma negação de um direito fundamental que é a educação [...] e se faz necessário em respeito primeiro a sua identificação na sua existência que é o nome ${ }^{13}$.

Ainda nesta mesma entrevista disponibilizada no canal do YouTube do Ministério da Educação, no dia 17 de janeiro de 2018, Toni Reis, militante histórico dos direitos LGBTQIA+, ao falar sobre esta Resolução, pontua "é um passo para a questão do respeito e a diminuição da evasão escolar, diminuição do bullying, da violência e da discriminação contra a população que é mais discriminada dentro da comunidade LGBTI".

Com o objetivo ainda de assegurar os direitos, tanto de maiores de idade como de menores, a Resolução manteve o texto sem quaisquer alterações:

Art. $3^{\circ}$ Alunos maiores de 18 (dezoito) anos podem solicitar o uso do nome social durante a matrícula ou a qualquer momento sem a necessidade de mediação.

Art. $4^{\circ}$ Alunos menores de 18 (dezoito) anos podem solicitar o uso do nome social durante a matrícula ou a qualquer momento, por meio de seus representantes legais, em conformidade com o

12 Seu Doutorado em Educação, defendido na Universidade Federal do Ceará (UFC) em 2012, teve como título Travestis na escola: assujeitamento e resistência à ordem normativa.

13 Disponível em: https://www.youtube.com/watch?v=TtCWI9N_uLw acesso em 20 ago. 2019 
disposto no artigo 1.690 do Código Civil e no Estatuto da Criança e do Adolescente. (BRASIL, 2018, p. 2)

Por fim, a resolução autoriza não apenas a utilização do nome social no cotidiano escolar como também a atualização cadastral 'do nome social de travestis e transexuais nos registros escolares da educação básica', possibilitando seus reconhecimentos a partir dos nomes autoidentificados.

\section{MARCOS LEGAIS SOBRE A UTILIZAÇÃO DO NOME SOCIAL NO ESTADO DE SÃO PAULO}

O primeiro registro de marco legal sancionado no estado de São Paulo ocorreu somente no dia 17 de março de 2010, por meio do Decreto Estadual $n^{\circ} 55.588 / 2010^{14}$ (SÃO PAULO, 2010), que dispõe sobre "tratamento nominal das pessoas transexuais e travestis nos órgãos públicos do Estado de São Paulo". O então Governador de São Paulo, José Serra (PSDB), compreendeu que um Estado democrático de direito deve reconhecer o princípio da dignidade humana onde, no caso de transexuais e travestis, o nome social é um direito irredutível para as suas identidades de gênero.

Tal decreto "dispõe sobre o tratamento nominal das pessoas transexuais e travestis nos órgãos públicos do Estado de São Paulo", e considera "que toda pessoa tem direito ao tratamento correspondente ao seu gênero; e que transexuais e travestis possuem identidade de gênero distinta do sexo biológico", assegurando "o direito à escolha de tratamento nominal nos atos e procedimentos promovidos no âmbito da Administração direta e indireta do Estado".

Por se tratar de uma primeira legislação sobre a temática no estado de São Paulo, surpreendeu positivamente o fato de, logo em seu Artigo 10, afirmou-se ficar "assegurado às pessoas transexuais e

\footnotetext{
${ }^{14}$ Ainda que o presente artigo verse sobre a utilização do nome social para estudantes transexuais e travestis, explicita-se, aqui, a existência de duas instruções na Unidade Central de Recursos Humanos (UCRH) do Estado de São Paulo que regulamentam o Decreto i) dentro do funcionalismo público estadual e ii) da utilização do nome social em concursos públicos. São elas, respectivamente: Instrução UCRH n 10 , de 01 de setembro de 2014, e Instrução UCRH nº 03, de 18 de fevereiro de 2015.
} 
travestis [...] o direito à escolha de tratamento nominal nos atos e procedimentos promovidos no âmbito da Administração direta e indireta do estado de São Paulo", ou seja, o uso do nome social foi regularizado e autorizado para pessoas transexuais e travestis que apenas requeressem sua utilização nos âmbitos da Administração direta e indireta do estado de São Paulo.

Com o objetivo de facilitar o requerimento e a consequente utilização do nome social, logo em seu $2^{\circ}$ artigo, afirma-se que a: "pessoa interessada indicará, no momento do preenchimento do cadastro ou ao se apresentar para o atendimento, o prenome que corresponda à forma pela qual se reconheça", prossegue, "identificada, reconhecida e denominada por sua comunidade e em sua inserção social" enquanto afirma ser quem é - em outras palavras, basta à pessoa se reconhecer enquanto tal e também ser reconhecida por terceiros de seu convívio social para ela requerer a utilização do nome social.

Ainda assim, o "registro civil deve ser utilizado para os atos que ensejarão a emissão de documentos oficiais, acompanhado do prenome escolhido", gerando diversas críticas por transexuais e travestis por se sentirem constrangides ${ }^{15}$ ao verem seus nomes de registro civil com destaque no documento oficial. A histórica demanda requeria um documento civil constando apenas o nome social, sem a exposição do registro civil evidenciado no documento.

Como era de se esperar, a demanda reprimida pela utilização de nome social não estava circunscrita apenas às travestis e transexuais já na fase adulta. O mesmo ocorria nas escolas de educação básica onde esta parcela populacional vivenciava cotidianamente processos de violências simbólicas e estigmatizações diversas (DUQUE, 2011; ANDRADE, 2012; BALIEIRO, 2014) como, por exemplo, no ato da chamada de conferência de presença realizada pelo professor, em informes nominais passados pelo corpo docente e diretivo da unidade escolar, dentre outros.

${ }^{15}$ Outra forma de se utilizar a linguagem não-binária: reconhecidxs, com o x no lugar do $e$. Há, ainda, quem se utilize do @ (como em reconhecid@s). Todavia, o e possibilita a inclusividade não somente na linguagem escrita como na falada. Portanto, optou-se pela utilização do e neste artigo. 
Com o intuito de atender a esta histórica necessidade, o governo do estado de São Paulo, em 30 de abril de 2014, por meio do Conselho Estadual da Educação (CEE), de no 125/2014 (SÃO PAULO, 2014), deliberou sobre a "inclusão de nome social nos registro escolares das instituições públicas e privadas no Sistema de Ensino do Estado de São Paulo". Em seu $1^{\circ}$ artigo, afirma-se: "as instituições vinculadas ao Sistema de Ensino do Estado de São Paulo [...] incluirão, a pedido dos interessados, além do nome civil, o nome social de travestis e transexuais nos registros escolares internos", sem a necessidade de comprovar documental e legalmente a sua necessidade.

Continua em seu artigo $2^{\circ}$ que, por se tratar de um local onde a idade dos alunos costuma estar abaixo da maioridade legal, de 18 anos, requere-se a "manifestação expressa dos pais ou responsáveis autorizando a inclusão do nome social", por escrito e a qualquer momento do percurso escolar daquela pessoa - podendo dificultar queestudantes transexuais e travestis sejam reconhecides como tal em virtude de uma família conservadora não aceitar as transexualidades e travestilidades.

A grande crítica a esta deliberação está no fato de o nome social não ser utilizado na emissão dos documentos certificadores de conclusão de curso, como o diploma e o histórico escolar, imputando uma violência psicológica desnecessária perante aquelas pessoas não identificadas com seus nomes civis (e consequente sexo biológico) ao 'serem lembradas' oficialmente, ao final do percurso escolar, de que as suas identidades de gênero não serão reconhecidas na certificação final, pois, em seu $6^{\circ}$ artigo afirma-se: "no histórico escolar, no certificado de conclusão e no diploma constará somente o nome civil" [grifo próprio].

O reconhecimento do nome social não deve ser apenas no ambiente interno da instituição de ensino, deve permear toda o tecido social com o objetivo de que cada vez mais transexuais e travestis possam vivenciar e performar as suas identidades de gênero sem a necessidade de serem lembrades, legal e documentalmente, que os seus sexos biológicos são diferentes de suas identidades de gênero - e isso ocorre exatamente quando a escola emite os documentos finais de alunes transexuais e travestis com somente 
seus nomes civis: lembra para estas pessoas e para toda a sociedade que a validade não é a forma como se reconhecem, e sim o que o discurso biomédico heteronormativo imputa aos seus corpos.

\section{REGISTRO QUANTITATIVO DE ALUNXS TT EM SÃO PAULO}

Para facilitar o entendimento sobre o levantamento quantitativo de alunes transexuais e travestis em São Paulo, esta seção foi dividida em duas subseções: i) no estado de São Paulo e ii) no município de São Paulo. Todos os dados foram conseguidos por meio da Lei de Acesso à Informação ${ }^{16}$ (BRASIL, 2011).

A necessidade dessa divisão se deu em virtude de os marcos legais estaduais serem anteriores aos marcos legais municipais e em virtude do projeto Transcidadania ser uma política pública específica onde visava a inserção social de transexuais e travestis no mercado de trabalho formal a partir da capacitação profissional conjuntamente com a escolarização daqueles evadides de suas escolas, não concluindo os estudos.

\section{Estado de São Paulo}

De acordo com os dados disponibilizados pela Secretaria Estadual de Educação, os requerimentos para a utilização de nome social por alunes transexuais e travestis começaram apenas em 2016 - dois anos após a deliberação no 125/2014, do CEE - e pôde-se observar uma crescente quantitativa em que, em seu ano inicial, obteve-se um total de 126 requerimentos, saltando para 389 requerimentos para a utilização do nome social em 2019.

O primeiro registro existente na Secretaria de Educação do Estado foi em 2016, onde 65 cidades tiveram um total de 126 estudantes requerendo a utilização do nome social em seus documentos oficiais, número este bastante expressivo frente à uma

\footnotetext{
${ }^{16}$ Regulamentada por meio da Lei № 12.527, de 18 de novembro de 2011, dipõe sobre os procedimentos a serem observados pela União, Estados, Distrito Federal e Municípios, com o fim de garantir o acesso a informações previsto no inciso XXXIII do art. $5^{\circ}$, no inciso II do $\S 3^{\circ}$ do art. 37 e no $\S 2^{\circ}$ do art. 216 da Constituição Federal (BRASIL, 2011).
} 
política pública de reconhecimento identitário aprovada dois anos antes e recém-implementada.

De acordo com os dados coletados por meio da LAl, o requerimento para a utilização de nome social ocorreu desde os primeiros anos do Ensino Fundamental I até $03^{\circ}$ ano do Ensino Médio. Quanto maior a idade discente, maior foi a quantidade de requisição para a utilização de nome social, conforme gráfico a seguir:

Gráfico 1 - Requerimento para a utilização de nome social em 2016

ALUNXS MATRICULADXS EM 2016

- 19ano m29ano

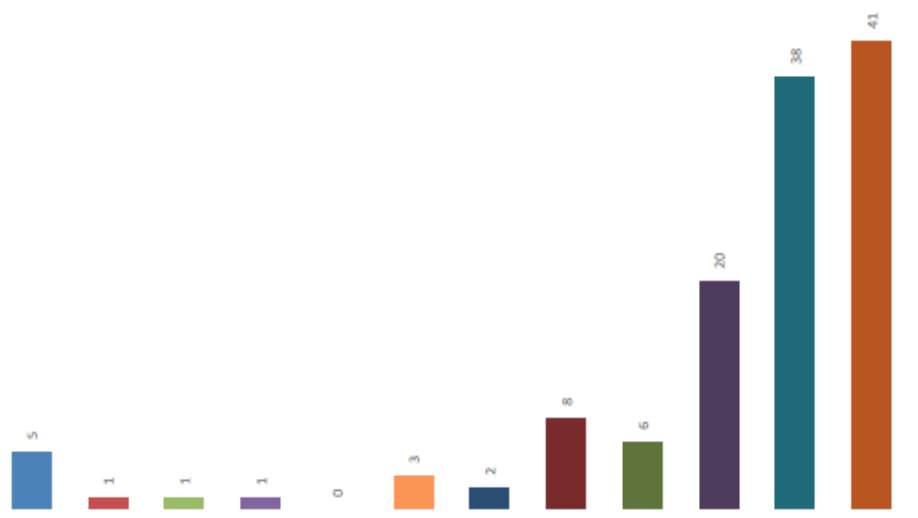

Fonte: Elaborado pelos autores (2021)

Atenta-se ao fato do abrupto aumento de requerimento no Ensino Médio, quando os alunes começam a se compreender melhor enquanto sujeites de direitos, com as suas demandas específicas e costumam empreender buscas por seus direitos.

O segundo registro existente na Secretaria de Educação do Estado foi em 2017, onde percebe-se a diminuição de cidades, caindo para 64 municípios, com requerimento para a utilização de nome social por estudantes, ao mesmo tempo em que houve um aumento quantitativo de 40 requerimentos, passando de 126 para 166 pedidos.

Esse aumento se dá pelo reconhecimento da existência de uma política pública que atendeu parcialmente às demandas desta 
parcela da sociedade, possibilitando que outros pedidos fossem protocolados às secretarias de suas instituições de ensino para a utilização do nome social. Afirma-se que atendeu parcialmente às necessidades em virtude do documento final de conclusão da escolarização ser emitido com o nome civil.

Ao contrário do ano anterior onde foi registrado o requerimento de 20 pedidos no $1^{\circ}$ ano de Ensino Médio, em 2017 houve um aumento para 28 pedidos. $O$ mesmo ocorreu com o $2^{\circ}$ ano de Ensino Médio, passando de 38 para 46 pedidos e, por fim, um significativo aumento nos pedidos registrados para $03^{\circ}$ ano de ensino médio, passando de 41 pedidos para 57, conforme gráfico a seguir.

Gráfico 2 - Requerimento para a utilização de nome social em 2017

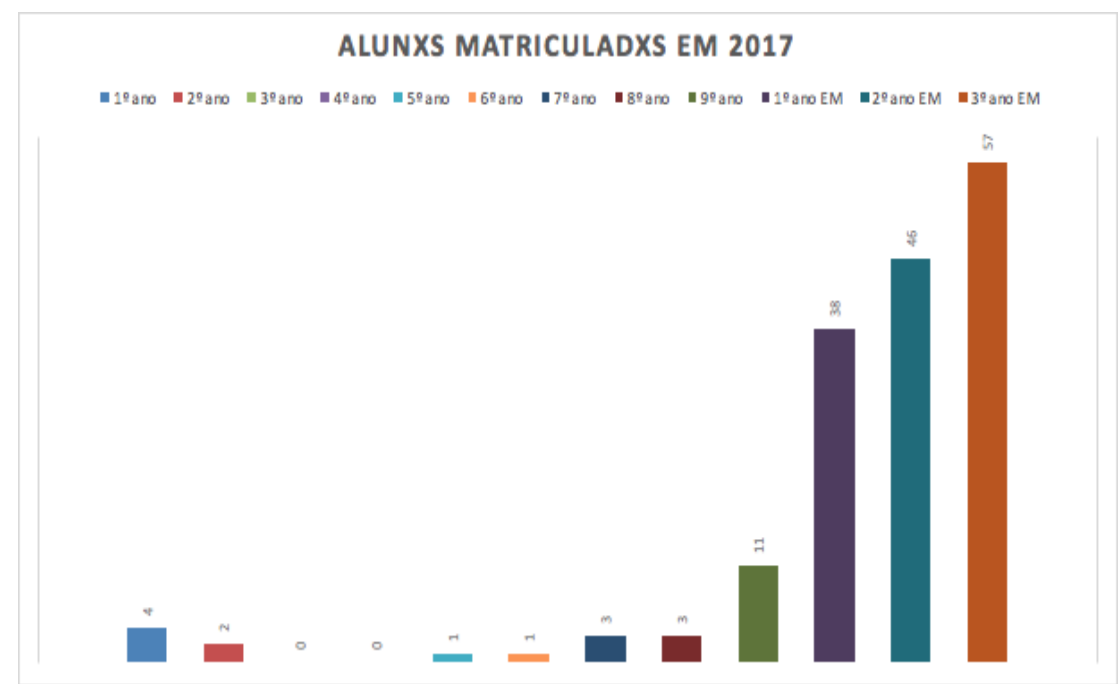

Fonte: Elaborado pelos autores (2021)

A quantidade de requerimentos de nome social para alunes do $9^{\circ}$ ano do Ensino Fundamental II dobrou, possibilitando crer na relação de quanto maior for a idade e escolaridade da pessoa, mais acesso ao conhecimento e informação ela obtém, possibilitando novas formas de vivências serem produzidas.

O terceiro registro existente na Secretaria de Educação do Estado é o de 2018, onde percebeu-se um expressivo aumento, tanto 
de cidades com estas demandas como em quantidade de alunes atendides. Houve um registro de 74 cidades e 331 estudantes utilizando nome social. Ou seja, um aumento de 10 municípios e 165 requerimentos, respectivamente.

Outro dado extremamente positivo está na quantidade de estudantes atendides em suas instituições de ensino, totalizando 91 requerimentos foram realizados no $1^{\circ}$ ano do Ensino Médio, 85 no $2^{\circ}$ do Ensino Médio e 86 no $3^{\circ}$ do Ensino Médio, concomitantemente foi registrado um aumento significativo de alunes em suas séries finais do Ensino Fundamental II, como no caso dos $7^{\circ}, 8^{\circ}$ e $9^{\circ}$ anos, conforme gráfico a seguir:

Gráfico 3 - Requerimento para a utilização de nome social em 2018

ALUNXS MATRICULADXS EM 2018

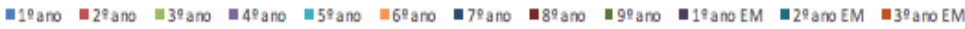

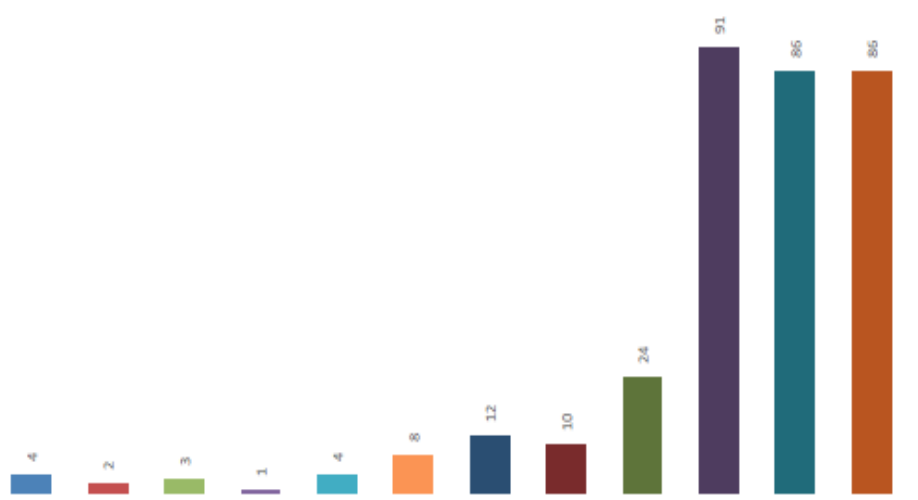

Fonte: Elaborado pelos autores (2021)

Reconhece-se a possibilidade destes dados terem aumentado consideravelmente pelo fato de que cada vez mais as questões relacionadas às transexualidades e travestilidades estão presentes nas mídias sociais, local esse permeado pelas juventudes (ZANCAN, TONO, 2018), e cada vez mais influencers digitais falarem abertamente sobre a temática em seus canais de Facebook, YouTube, Instagram e Twitter. Entretanto, ressalta-se o fato de neste mesmo período o Brasil vivenciar uma guinada ao conservadorismo 
(ACOSTA, 2018), dificultando uma melhor efetivação de políticas públicas voltadas a travestis e transexuais.

Por fim, no ano de 2019, foram registrados 75 cidades com requerimento para a utilização de nome social realizado por 389 estudantes. Os dados seguiram o padrão dos anos anteriores onde, quanto maior a idade discente, maior a quantidade de requerimentos registrados, com salto maior no Ensino Médio.

Gráfico 4 - Requerimento para a utilização de nome social em 2019

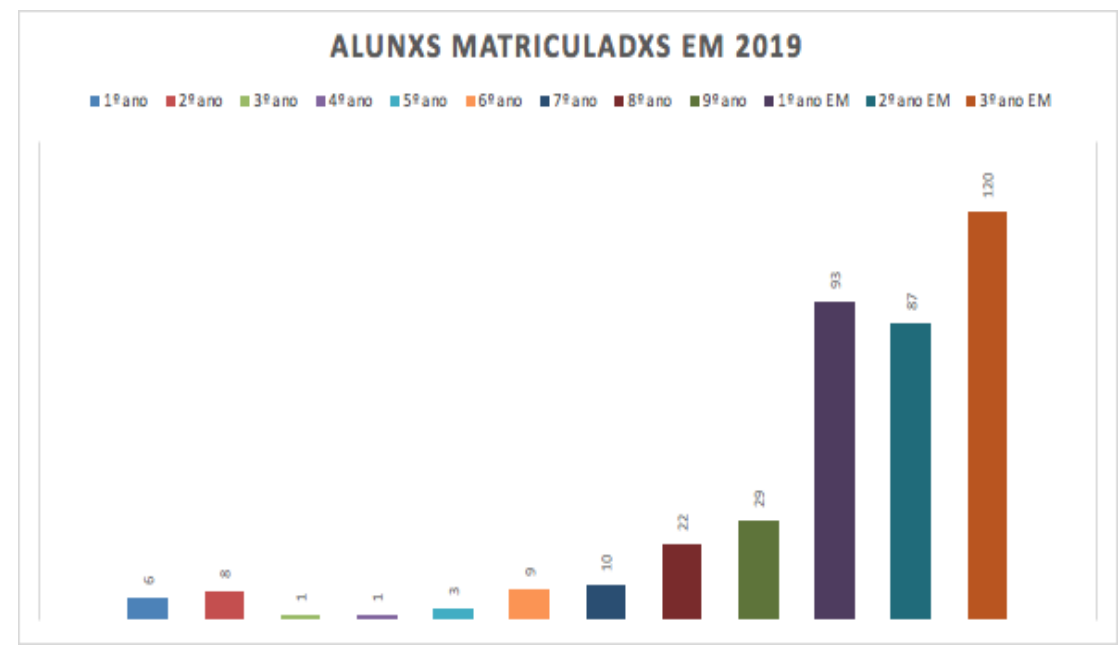

Fonte: Elaborado pelos autores (2021)

É preciso atentar, e até mesmo estranhar, o fato de a existência de diversos registros ao longo dos anos feitos por alunes transexuais e travestis com idades inferiores à 10 anos nas instituições de ensino, como no caso daqueles matriculades nas séries iniciais do Ensino Fundamental I. O estranhamento está no reconhecimento da dificuldade de acesso às unidades de saúde especializadas em transexuais e travestis conjuntamente com o conhecimento limitado de professores sobre estas questões (ACOSTA, 2016), ao mesmo tempo em que a sociedade em geral também produz discursos conservadores, discriminatórios e estigmatizantes sobre transexuais e travestis, dificultando o reconhecimento de suas existências em idades das séries iniciais do Ensino Básico. Estas singularidades dificultam a possibilidade de os responsáveis das crianças e as 
unidades de ensino reconhecerem com facilidade a existência de crianças transexuais ou travestis.

Outra questão a se considerar está na não existência de nenhum registro de requerimento, por parte do Governo do Estado de São Paulo, para a utilização de nome social ao longo destes quatro anos analisados nas instituições de ensino provedoras de Educação de Jovens e Adultos $^{17}$, pois no referido período houve a implementação do programa Transcidadania, o qual possibilita aos alunes transexuais e travestis retornarem aos estudos do ensino básico conjuntamente com ensino profissionalizante.

Embora o Transcidadania tenha sido um programa educacional a nível municipal e os dados desta seção terem sido colhidos com a Secretaria de Educação do Estado de São Paulo, não houve qualquer registro da utilização de nome social por parte de alunes transexuais e travestis cursando a Educação de Jovens e Adultos - motivo esse explicado na próxima seção.

\section{Município de São Paulo}

A preocupação evidenciada no último parágrafo da seção anterior foi comprovada a partir da resposta obtida sobre os dados requeridos por meio da LAl, em que a Prefeitura de São Paulo informou que o campo para a indicação de nome social aos alunos no sistema de cadastro e matrículas só foi disponibilizado em 2015.

Informaram-nos que, desde a implementação deste direito, ações de capacitação aos corpos técnicos são desenvolvidas para o devido preenchimento do sistema, uma vez que foi identificado erros diversos na coleta de dados. Como estes dados foram obtidos via requerimento da $L A I$, no corpo da mensagem de resposta obtida por nós, constava ainda, como exemplo de inconsistências identificadas, a repetição do nome da criança, em todas as idades, inclusive na etapa da creche. Conforme resposta obtida, no período entre 2015-

\footnotetext{
${ }^{17}$ Em virtude de todos os indicadores dos 4 anos constarem nenhum requerimento para a utilização de nome social na EJA, optou-se em não demonstrar estas informações no gráfico com o objetivo de que os dados não ficassem pequenos, dificultando a leitura. Mas, ainda assim, explicita-se que nos dados recebidos constatou-se a inexistência de qualquer indicador de requerimento para a utilização do nome social.
} 
2018 é impossível de identificar quais estudantes realmente requisitaram o uso do nome social e, como essa inconsistência foi identificada apenas no final de 2018, tornou-se obrigatória, a partir de $1 / 7 / 2019$, a assinatura do requerimento para uso de nome social a proteção e garantia de direitos de alunes transexuais e travestis.

Entretanto, tais informações poderiam estar disponibilizadas há mais tempo, mesmo porque, em relação à administração pública do município de São Paulo, o Decreto 51180/2010, de São Paulo (14/01/20), já dispunha "sobre a inclusão e uso do nome social de pessoas travestis e transexuais nos registros municipais relativos a serviços públicos prestados no âmbito da Administração Direta e Indireta" (MARANHÃO Fo, 2012, p. 43).

Em virtude do que é explicado pela Prefeitura de São Paulo logo acima, impossibilitou-se de precisar a quantidade de alunes transexuais e travestis que requisitaram a utilização do nome social em suas instituições de ensino ao longo dos últimos anos. Apenas no ano de 2019 houve o devido registro, totalizando 3 estudantes no Ensino Fundamental II, 23 estudantes na Educação de Jovens e Adultos e 1 estudante no Ensino Médio. Dados esses que não estão alinhados com os mesmos registrados pelo Governo do Estado de São Paulo.

Além das normativas federais, estaduais e municipais, é preciso que os regimentos escolares ${ }^{18}$ também dêem conta de estimularem e provocarem o devido respeito às pessoas transgêneras em geral (inclusas as que se auto determinam travestis e transexuais). Luma Andrade infere que "no regimento escolar, encontramos os direitos e os deveres de gestores(as), professores(as), funcionários(as) e alunos(as), além da supremacia do(a) diretor(a) sobre os demais", e que dentre os direitos de discentes, muitas vezes destacam-se "respeito, compreensão e amor para com os(as) alunos(as)", desde que tais pessoas estejam "enquadrados(as) nas normas da escola, as

${ }^{18} \mathrm{O}$ regimento escolar é assim definido por Luma Andrade: "texto legitimado pelo CEC para que a escola seja reconhecida legalmente. Neste documento, encontramos todos os direitos e deveres de todos(as) que fazem a escola. Ele deve ser construído coletivamente com a participação de todos os segmentos da escola". (ANDRADE, 2012, p. 179). 
quais por sua vez reproduzem a visão hegemônica da sociedade". (ANDRADE, 2012, p. 184).

E é esta visão hegemônica, enfeixada em um determinado dispositivo da cis-heteronorma (MARANHÃO Fo, 2017) que faz com que a travesti na escola ainda seja considerada um problema pois:

não aceitam seu modo de ser, não reconhecem as vestes, os acessórios, a maquiagem ou o nome social. Não aceitam o gênero feminino, não permitem que ela use o banheiro de sua escolha, sendo instigada diariamente a rever seu comportamento, a mudar de cultura e se inserir no gênero masculino. (ANDRADE, 2012, p. 184).

Luma indaga: "por que respeito, compreensão e amor não são acessíveis às travestis? Por que elas são maltratadas por alunos(as), professores(as), funcionários(as) e gestores(as)? Que alunos(as) têm este direito garantido? (ANDRADE, 2012, p. 184).

\section{CONSIDERAÇÕES FINAIS}

Sabemos que o uso do nome social por travestis e transexuais nas escolas tem um efeito apenas paliativo: ameniza o problema, mas não o resolve completamente. Muitas estratégias de inclusão deveriam ser adotadas ainda para dirimir o constante desrespeito, intolerância e violência perpetradas não só a pessoas que adotam estas identidades específicas como à comunidade transgênera em geral.

Mas é de fundamental importância que o uso de nome social seja corretamente implementado no ambiente escolar e sempre respeitado. Além disso, não só pessoas que se autodesignam travestis e transexuais, como outras pessoas transgêneras deveriam ter 0 mesmo acolhimento e direito de se identificarem conforme os nomes que lhe são preciosos.

Além do adequado uso do nome social, é necessário atentar à flexão de gênero em que a pessoa aprecia ser chamada. A maioria das travestis brasileiras, por exemplo, gosta de ser chamada no feminino, e é assim que devem ser referidas. Como questiona Luma 
de Andrade, "assim como eu, minhas interlocutoras preferem ser chamadas pelo nome feminino, principalmente em lugares públicos como a escola, mas será que alunos(as), professores(as), gestores(as) concordam com esta forma de tratar a travesti?" (ANDRADE, 2012, p. 208).

Certa e lamentavelmente o respeito ao nome social e flexão de gênero nem sempre se concretiza, como a própria Luma demonstra em sua tese (ANDRADE, 2012). É, assim, de fundamental importância a atenção aos modos como a pessoa se assume, se aceita, se identifica, e quer ser interpelada. Luma comenta que "quando chamada pelo nome masculino, alguns colegas aproveitam para zombar das travestis, elas passam a ser piadas, motivos de gracinhas. Magoadas com tamanho constrangimento, algumas preferem desistir da escola". (ANDRADE, 2012, p. 209). Assim, fica evidente que uma das razões para a evasão escolar está nas humilhações sofridas pelas pessoas trans*.

Cabe a nós a responsabilidade, nesse cenário catastrófico, dos estudos que visam a educação sexual, a justiça e a igualdade de gênero. Inclusive, é "possível dizer que quando uma travesti é assassinada temos, enquanto sociedade, algum tipo de responsabilidade" e pode ser que "por nosso silêncio anuente carreguemos no caixão cada travesti (e cada pessoa transgênera) que é assassinada", e que "é necessário tomarmos partido e atuarmos na educação." (MARANHÃO Fo, 2017, p. 207). Aliás, essa assertiva vale não tão somente para travestis, mas para transexuais e para toda e qualquer pessoa transgênera.

É necessário o estímulo a uma educação empática e solidária que valorize o respeito, inclusive e principalmente o respeito às emoções, afetos e sensibilidades alheias. Neste sentido, as emoções estão diretamente relacionadas ao modo como a pessoa entende, assume e aceita o seu corpo, manifestando assim sua subjetividade e expressando o modo como se identifica: como ela é, e como ela está no mundo. 


\section{REFERÊNCIAS}

ACOSTA, T. Evasão ou expulsão escolar de gays efeminados e travestis das instituições escolares e as vidas que não podem ser vividas. Bagoas - Estudos gays: gêneros e sexualidades, v. 13, n. 20, 27 ago., 2019

ACOSTA, T. Gêneros e sexualidades na escola em tempos de conservadorismo censor policialesco. In: DICKMANN, I. [org.]. Rumos da Educação. 1. ed. São Paulo: Dialogar, 2018, v. 1, p. 211227.

ACOSTA, T. Morrer para nascer travesti: performatividades, escolaridades e a pedagogia da intolerância. Dissertação de Mestrado, UFSCar, 2016.

ANDRADE, L. Travestis na escola: assujeitamento e resistência à ordem normativa. Tese (doutorado). Programa de Pós-Graduação em Educação, Faculdade de Educação, Universidade Federal do Ceará, Fortaleza, 2012.

BALIEIRO,F. F.; RISK, E. N. Escola e sexualidade: uma visão crítica à normalização. In.: MISKOLCI, R.; LEITE JUNIOR, J. Diferença na educação: outros aprendizados. EDUFSCar, 2014.

BRASIL. Lei No 12.527, de 18 de novembro de 2011. Regula o acesso a informações previsto no inciso XXXIII do art. $5^{\circ}$, no inciso II do § $3^{\circ}$ do art. 37 e no $\S 2^{\circ}$ do art. 216 da Constituição Federal; altera a Lei $n^{\circ} 8.112$, de 11 de dezembro de 1990; revoga a Lei $n^{\circ} 11.111$, de 5 de maio de 2005, e dispositivos da Lei $n^{\circ} 8.159$, de 8 de janeiro de 1991; e dá outras providências. Diário Oficial da União: Brasília, DF, 18 nov. 2011. Disponível em:

www.planalto.gov.br/ccivil_03/_ato2011-2014/2011/lei/l12527.htm. Acesso em: 21 maio 2020.

BRASIL. Ministério da Educação. Conselho Nacional da Educação. Parecer CNE/CP n 14/2017. Normatização nacional sobre o uso do nome social na educação básica. 2017. Disponível em portal.mec.gov.br/index.php?option=com_docman\&view=download 
\&alias=72921-pcp014-17-pdf\&category_slug=setembro-2017pdf\&ltemid=30192. Acesso em 21 maio 2020.

BRASIL. Ministério da Educação. Conselho Nacional de Educação. Conselho Pleno. Resolução No 1, de 19 de janeiro de 2018. Resolução CNE/CP 1/2018. Diário Oficial da União, Brasília, 22 de janeiro de 2018, Seção 1, p. 17.

DUQUE, T. Montagens e desmontagens: desejo, estigma e vergonha entre travestis adolescentes. São Paulo, Annablume: 2011.

FACCHINI, R. Sopa de letrinhas. Movimento homossexual e produção de identidades coletivas nos anos 90. Garamond, 2005.

GONÇALVES DA SILVA, C.; LIONÇO, T. Temas perigosos para educação? Juventudes, instituições de ensino, gênero e sexualidades. Revista Inter Ação, v. 44, n. 1, p. 180-195, 22 maio 2019.

LANZ, L. O corpo da roupa: a pessoa transgênera entre a transgressão e a conformidade com as normas de gênero.

Dissertação (Mestrado em Sociologia). Programa de Pós-graduação em Sociologia. Universidade Federal do Paraná, Curitiba, 342 p., 2014.

MARANHÃO Fo, E. M. A. Apresentando conceitos nômades: entregêneros, entremobilidades, entresexos, entreorientações.

História Agora, São Paulo, v.1, n. 14, p. 17-54, 2012.

MARANHÃO Fo, E. M. A. (Re/des)conectando gênero e religião. Peregrinações e conversões trans ${ }^{*}$ e ex-trans* em narrativas orais e do Facebook. Tese (Doutorado). Programa de Pós-graduação em História Social. Orientação de José Carlos Sebe Bom Meihy. Universidade de São Paulo. São Paulo, 2014.

MARANHÃO Fo, E. M. A. A travesti morreu mas carrego ela no caixão" e outras histórias vivas: conversão, transfobia religiosa e morte. Revista Brasileira de História das Religiões. ANPUH, ano 10, n. 29, 2017.

MARANHÃO Fo, E. M. A. Anotações sobre a "inclusão" de travestis e transexuais a partir do nome social e mudança de prenome. In: 
MARANHÃO Fo, E. M. A (Org.). Dossiê (In) Visibilidade Trans 1.

História Agora, São Paulo, v.1, n. 15, p. 29-59, 2013.

PELÚCIO, Larissa; MISKOLCl, Richard A prevenção do desvio: o dispositivo da aids e a repatologização das sexualidades dissidentes Sexualidad, Salud y Sociedad. Revista Latinoamericana, n. 1, p. 125-157, 2009. Disponível em

https://www.redalyc.org/pdf/2933/293322961007.pdf. Acesso em 21 maio 2020.

SÃO PAULO (Estado). Conselho Estadual da Educação (CEE), de $n^{\circ}$ 125/2014. Dispõe sobre a inclusão de nome social nos registros escolares das instituições públicas e privadas no Sistema de Ensino do Estado de São Paulo e dá outras providências correlatas. Diário Oficial do Estado, 1 maio de 2014. Disponível em:

www.portal.cps.sp.gov.br/cetec/geral/legislacao/estadual/cee/125_2 014.docx. Acesso em: 30 ago. 2019.

SÃO PAULO (Estado). Decreto No 55.588, de 17 de março de 2010. Dispõe sobre o tratamento nominal das pessoas transexuais e travestis nos órgãos públicos do Estado de São Paulo e dá providências correlatas. Casa Civil, 17 de março de 2010. Disponível em:

https://www.al.sp.gov.br/repositorio/legislacao/decreto/2010/decret o-55588-17.03.2010.html. Acesso em: 30 ago. 2019.

TORRES, M.A.; PRADO, M. A. Professoras transexuais e travestis no contexto escolar: entre estabelecidos e outsiders. Educ. Real., Porto Alegre, v. 39, n. 1, p. 201-220, mar. 2014 . Disponível em: <http://www.scielo.br/scielo.php?script=sci_arttext\&pid=S217562362014000100012\&lng=en\&nrm=iso >. Acesso em 21 maio 2020. http://dx.doi.org/10.1590/S2175-62362014000100012.

ZANCAN, C. R. B.; TONO, C. C. P. Hábitos dos adolescentes quanto ao uso das mídias digitais. EDUCA - Revista Multidisciplinar em Educação, v.5, n. 11, p. 98-119, maio/ago, 2018.

Submetido em: Julho/ 2020.

Aceito em: Fevereiro/ 2021. 